\title{
Adenomatoid Odontogenic Tumour - The Master of Disguise
}

\author{
Shreyas N. Shah ${ }^{1}$, Falguni Patel ${ }^{2}$, Vandana Shah ${ }^{3}$ \\ 1, 2,3 Department of Oral \& Maxillofacial Pathology and Microbiology, K.M. Shah Dental College and Hospital, \\ Sumandeep Vidyapeeth, Deemed to Be University, Vadodara, Gujarat, India.
}

\section{INTRODUCTION}

Adenomatoid odontogenic tumour, truly coined as one of the masters of disguise of orofacial pathologies, was first reported in the literature by Steen Lands. ${ }^{1}$ Philipson and Brin used the terminology adenomatoid odontogenic tumour for this pathology with its commonly accepted abbreviation AOT. ${ }^{2}$ Later on, adenomatoid odontogenic tumour (AOT) name was accepted by the World Health Organization (WHO) in 1971. In 2005, WHO revealed the histological variants of the adenomatoid odontogenic tumour and classified it as a tumour comprised of odontogenic epithelium showing various patterns in histopathologic view within a mature connective tissue stroma. ${ }^{3}$ It is seldom noticed neoplasm which comprises only $3 \%$ of all the odontogenic tumours. It was commonly found in the maxilla with female predilection and mostly in association with impacted canines.4-6

Adenomatoid odontogenic tumour is an odontogenic epithelial tumour usually seen in females in their second decade of life. The tumour is slow growing in nature which eventually results in painless expansion of jaw. The maxilla is commonly affected than mandible. Being benign in nature, most of the AOT cases usually got treated with conservative surgical enucleation but the greater size of tumour can leave behind an oro-facial defect. To prevent such type of incident, it is important to diagnose them early and treat accordingly. Herewith, we are presenting a case report of adenomatoid odontogenic tumour of mandible in a male patient.

\section{PRESENTATION OF CASE}

In the Department of Oral Pathology and Microbiology, a 14-year-old male patient reported with a swelling in the lower part of the face for 1 month [Figure $1 \mathrm{~A}$ ]. Patient gave a history of trauma due to fall from cycle 3 months back. As mentioned by the patient there was gradual increase in the size of the swelling over the lower jaw since last 1 month. The medical history of the patient was unremarkable.

On inspection, an ovoid, extra oral swelling was noticed on the lower border of the mandible extending up to the angle of mandible on the right side. On palpation, egg-shell crackling was elicited. There was Localised rise in temperature and the skin over the swelling did not show any colour changes. When inspected intraorally, the lesion extended from the molar region on the right side to premolar region on the left side, measuring about $3 \mathrm{~cm}$ in diameter which was soft in consistency and non-tender [Figure 1B]. Mobility of the teeth was noticed with 31, 32 and 44 along with obliteration of the buccal vestibule.

The orthopantomogram revealed ovoid radiolucency extending from the molar region on the right side to premolar region on the left side involving the crown portion of developing permanent canine of the right side. Thinning of the cortical plate was seen at the lower border of the mandible [Figure 2].
Corresponding Author: Dr. Shreyas N. Shah,

Reader,

Department of Oral \& Maxillofacial Pathology and Microbiology,

K. M. Shah Dental College and Hospital, Sumandeep Vidyapeeth

Deemed to Be University,

Piparia-391760, Vadodara, Gujarat, India.

E-mail: vrajdent@gmail.com

DOI: $10.14260 / j e m d s / 2021 / 178$

How to Cite This Article:

Shah SN, Patel F, Shah V. Adenomatoid odontogenic tutor - the master of disguise. J Evolution Med Dent Sci 2021;10(11):835838, DOI: $10.14260 /$ jemds/2021/178

Submission 05-12-2020,

Peer Review 21-01-2021,

Acceptance 27-01-2021,

Published 15-03-2021.

Copyright (C) 2021 JEMDS. This is an open access article distributed under Creative Commons Attribution License [Attribution 4.0 International (CC BY 4.0)] 

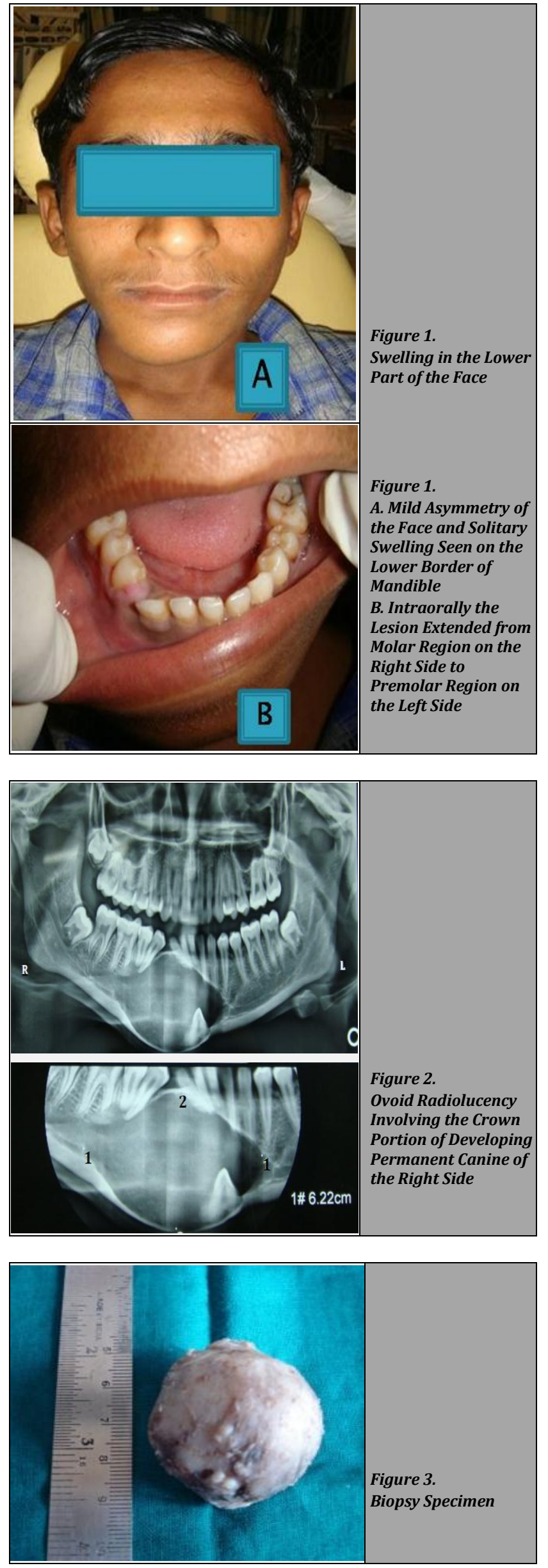
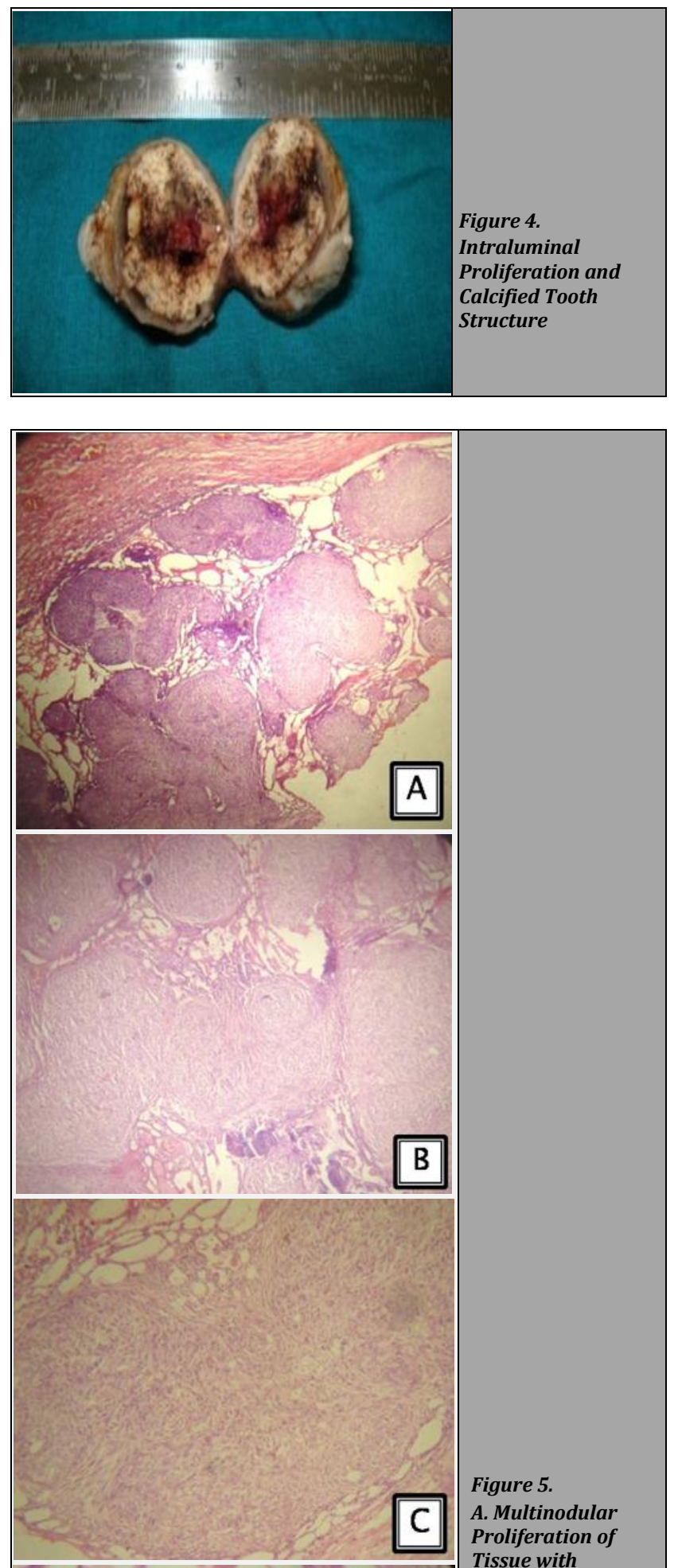

Figure 5.

A. Multinodular Proliferation of

Tissue with

Haemorrhage and Extravasated RBCs

$B$. Spindle and Cuboidal Cells Arranged in Swirls and Presence of osteoid Like Material

C. Cells Arranged in Duct Like Pattern

D. Spindle and

Cuboidal Cells in

Rosette Pattern 


\section{CLINICAL DIAGNOSIS}

Adenomatoid odontogenic tumour

\section{DIFFERENTIAL DIAGNOSIS}

- Dentigerous cyst

- Ameloblastoma

\section{DISCUSSION OF MANAGEMENT}

Surgical intervention was carried out under anaesthesia and the lesion was enucleated in toto. The enucleated lesion opined for histopathological assessment.

\section{PATHOLOGICAL DISCUSSION}

\section{Gross Features}

Grossly it was greyish in colour, oval shaped, soft in consistency, measuring approximately about $4.5 \times 3.7 \times 1.9 \mathrm{~cm}$ [Figure 3]. After cutting the specimen into two halves, one half of the specimen showed presence of a tooth and the entire specimen showed intraluminal proliferative growth [Figure 4].

\section{Histopathological Findings}

On microscopic examination, haematoxylin and eosin stained sections showed multinodular proliferation of spindle and cuboidal cells in swirls, rosette and duct like pattern. At the peripheral region of the lesion a thick connective tissue capsule was noticed. Few areas showed osteoid like material which was eosinophilic. Haemorrhage and extravasated RBCs were noted in few areas [Figure 5].

\section{FINAL DIAGNOSIS}

Adenomatoid odontogenic tumour

\section{DISCUSSION}

Benign, hamartomatous and non-aggressive lesion, adenomatoid odontogenic tumour shows slow but progressive growth. However, the pathogenesis of AOT is unknown. Stafne (1948), suggested that, the entrapped epithelium in the line of fusion could be the cell of the origin in case of AOT. Other studies revealed, odontogenic epithelium, inner enamel epithelium, outer enamel epithelium, dental lamina or its remnants, cell rests of Malassez, as cell of the origin for AOT.7,8

AOT accounts for around $3-7 \%$ of the entire odontogenic tumours. Only 750 cases have been reported in the literature. Adenomatoid odontogenic tumours are commonly found in young individuals with maximum no of cases notice in $2^{\text {nd }}$ decade of life. It is found to be frequently associated with un- erupted canines and usual site of occurrence at the anterior part of upper and lower jaws. These features were evident in present case. AOT shows female predilection as compared to male, ${ }^{9}$ but here we noticed it in male patient.

The pathological variants of AOT are follicular, extrafollicular and peripheral, all of them are having similar histological characteristics. The Follicular variant of AOT shows simply a central lesion in association with an impacted tooth, whereas extrafollicular variant shares similarity in its structure with follicular variant but has no relation with the impacted tooth and usually develops around the adjacent teeth. Sometimes it also shows superimposition with adjacent teeth. ${ }^{10-12}$ The present case revealed follicular variant of AOT.

Radiographically, such lesions share similar features with other odontogenic origin lesions. However, these characteristics chiefly depend on tumour type. A well developed and circumscribed area in association with the crown or root of an impacted tooth is characteristic feature of the follicular variant. The extra-follicular variant is usually observed to be placed in between or over the roots of an erupted tooth. Whereas, thinning or resorption of the cortical bone can be observed in the peripheral variant. In some cases, tooth displacement without causing root resorption also be figured out in peripheral type. ${ }^{13,14}$ The present case showed follicular type of radiographic pattern.

Microscopically, adenomatoid odontogenic tumour shows spindle epithelial cells in a form of cords, nests or cell masses in a scanty fibrous stroma. A central space, empty or filled with eosinophilic material, surrounded by epithelial cells form a characteristic rosette pattern in the lesional tissue of AOT. There is also evidence of duct-like structures, either prominent, sparse or even absent and are composed of cuboidal or columnar cells with peripheral nuclei surrounding a central space. The presence of small focus of calcification scattered throughout the tumour, reveals features of abortive formation of enamel / dentine / cementum. ${ }^{1,15}$ All of the abovementioned histopathological features were observed in present case.

This lesion being benign in nature and well encapsulated in structure, the preferred choice of treatment is conservative surgical enucleation. ${ }^{7,15}$ The large lesions are usually treated with surgical enucleation along with the extraction of adjacent teeth due to lack of supporting bone. Marsupialisation or decompression of the lesion is referred to as treatment of choice in case of lesions associated with the tooth favouring orthodontic movement. Recurrence rate is rare $(0.2 \%) .{ }^{16}$ In the present case, surgical enucleation was performed and there was no recurrence noticed during follow-up visits.

Financial or other competing interests: None.

Disclosure forms provided by the authors are available with the full text of this article at jemds.com.

\section{REFERENCES}

[1] Mohamed A, Singh AS, Raubenheimer EJ, et al. Adenomatoid odontogenic tumour: review of the literature and an analysis of 33 cases from South Africa. Int J Oral Maxillofac Surg. 2010;39(9):843-6.

[2] Philipsen HP, Birn H. The adenomatoid odontogenic tumour. Ameloblastic adenomatoid tumour or adeno- 
ameloblastoma. Acta Pathol Microbiol Scand 1969;75(3):375-98.

[3] Garg D, Palaskar S, Shetty VP, et al. Adenomatoid odontogenic tumor - hamartoma or true neoplasm: a case report. J Oral Sci 2009;51(1):155-9.

[4] Adisa AO, Lawal AO, Effiom OA, et al. A retrospective review of 61 cases of adenomatoid odontogenic tumour seen in five tertiary health facilities in Nigeria. Pan Afr Med J 2016;24:102.

[5] Seo WG, Kim CH, Park HS, et al. Adenomatoid odontogenic tumor associated with an unerupted mandibular lateral incisor: a case report. J Korean Assoc Oral Maxillofacial Surg 2015;41(6):342-5.

[6] Batra P, Prasad S, Parkash H. Adenomatoid odontogenic tumour: review and case report. J Can Dent Assoc 2005;71(4):250-3.

[7] Tchertkoff V, Daino JA, Ehrenreich T. Ameloblastic adenomatoid tumor (adenoameloblastoma). Case reports and review of the literature. Oral Surg Oral Med Oral Pathol 1969;27(1):72-82.

[8] Philipsen HP, Samman N, Ormiston IW, et al. Variants of the adenomatoid odontogenic tumor with a note on tumor origin. J Oral Pathol Med 1992;21(8):348-52.

[9] Neville BW, Damm DD, Allen CM, et al. Oral and maxillofacial pathology. $3^{\text {rd }}$ edn. Saunders Elsevier 2009:713-5.
[10] Seo WG, Kim CH, Park HS, et al. Adenomatoid odontogenic tumor associated with an unerupted mandibular lateral incisor: a case report. J Korean Assoc Oral Maxillofac Surg 2015;41(6):342-5.

[11] Dayi E, Gürbüz G, Bilge $O M$, et al. Adenomatoid odontogenic tumour (adenoameloblastoma). Case report and review of the literature. Aust Dent J 1997;42(5):3158.

[12] Krishnamurthy K, Balaji RS, Devadiga S, et al. Adenomatoid odontogenic tumor in the maxillary antrum: a rare case entity. J Pharm Bioallied Sci 2014;6(Suppl 1):S196-9.

[13] Handschel JG, Depprich RA, Zimmermann AC, et al. Adenomatoid odontogenic tumor of mandible review of the literature and report of a rare case. Head Face Med 2005;1:3.

[14] Toida M, Hyodo I, Okuda T, et al. Adenomatoid odontogenic tumor: report of two cases and survey of 126 cases in Japan. J Oral Maxillofac Surg 1990;48(4):404-8.

[15] Philipsen HP, Reichart PA. Adenomatoid odontogenic tumour: facts and figures. Oral Oncol 1999;35(2):125-31.

[16] Shetty K, Vastardis S, Giannini P. Management of an unusually large adenomatoid odontogenic tumor. Oral Oncology Extra 2005;41(10):316-8. 